\title{
VALUE ADDED CREATED BY INDUSTRY “EDUCATION” IN BALTIC STATES AND FINLAND
}

\author{
Andrejs Jaunzems \\ Ventspils University of Applied Sciences, Latvia \\ jaunzems@venta.lv
}

\begin{abstract}
The goal of this paper is to carry out a comparative analysis of value added as part of total output created by the industry P85 (Education) in the Baltic States and Finland in order to find an answer to the following question: "How realistic is a significant value added increase by the industry P85 in Latvia in the nearest years?" The empirical material of the research is the National Input-Output Tables for the Period 20002014 available on the World Input-Output Database with its unified structured statistical information in monetary terms. The theoretical background of the current research is the Input-Output analysis, which is further explored, for example, in the book Input-Output Analysis. Foundations and Extensions by Ronald E. Miller and Peter D. Blair and in some other scientific publications as well. The original version of the Input-Output model created by the author allows to calculate and to interpret the interindustry coefficients, Leontief inverse, allocation coefficients and Ghosh inverse. The author conducts a comparative analysis of direct and total linkages, backward and forward linkages of the industry P85 in the Baltic States and Finland in 2014 to estimate the impact of the increasing gross output in P85 on the national economy. The discussion part and conclusions of the paper are devoted to indetifying the most important factors, which cause significant growth of value added of the industry P85 in Latvia. The main conclusion: the most realistic way to attain an increase in value added of the industry P85 in Latvia is to encourage the export component of final demand with the help of well-organized higher education marketing.
\end{abstract}

Keywords: industry P85 (Education), Input-Output model, value added, interindustry coefficients, Leontief inverse, allocation coefficients, Ghosh inverse.

\section{Introduction}

The aim of the presented study paper is to carry out a comparative analysis of value added as part of total output created by the industry P85 (Education) in the Baltic States and Finland in order to find an answer to the following question: "How realistic is a significant value added increase by the industry P85 in Latvia in the nearest years?" For this purpose, the impact of gross output growth and value added growth in P85 on the national economy as a whole is investigated.

The empirical material of the study is the National Input-Output Tables for the Period 2000-2014 (NIOT) available thanks to World Input-Output Database (WIOD) with its unified structured statistical information in monetary terms (www.wiod.org). According to NIOT the United Nations 3-letter codes are used: EST (Estonia), FIN (Finland), LVA (Latvia), LTU (Lithuania). The Illustrated User Guide to the World Input-Output Database is given by Timmer M. P., Dietzenbacher E., Los B., Stehrer R., de Vries G. J. (2015). Data for 56 sectors are classified according to the International Standard Industrial Classification (ISIC) revision No. 4. The products are classified according to the statistical classification of products by activity, abbreviated as CPA. Classification of products (goods and services) covers 56 product categories following the primary outputs from 56 sectors. The NIOT are compiled in current prices, expressed in millions of US dollars. The Input-Output tables have an industry-by-industry format, as many applications require such a square matrix reflecting the economic linkages across industries. They represent the direct and dual systems of accounting balancing equations in millions of dollars. The author has accepted the NIOT as a reliable source of information and the NIOT are assumed in the current research as indisputable. The latest NIOT available right now is for 2014. Nevertheless, this is the reason to expect that WIOD will be carried on also for the further time and WIOD will grow as a very fruitful empirical inventory for scientific and management needs.

The general theoretical background of the current study in the wide sense is the Input-Output analysis offered by Leontief [1] and Ghosh [2]. The current content of the Input-Output analysis is explored, for example, in the book Input-Output Analysis. Foundations and Extensions by Ronald E. Miller, Peter D. Blair [3] and in a number of academic publications. The theoretical framework of this paper is directly connected with the theoretical background of the paper by Jaunzems (2018), where the original Input-Output model as adapted for NIOT is offered. The original version of the InputOutput model allows to calculate and to interpret the interindustry coefficients, Leontief inverse, 
allocation coefficients and Ghosh inverse. In addition, the geometry of Euclidean space $R^{n}$ as a mathematical tool plays an important role in this paper.

The discussion part and conclusions of the paper are devoted to identifying the most important factors, which cause significant growth of value added of the industry P85 in Latvia. The author conducts a comparative analysis of direct and total linkages, backward and forward linkages of the industry P85 in the Baltic States and Finland in 2014 to estimate the impact of the increasing gross output and final demand in P85 on the national economy. The comparative approach allows us to recognize differences and analogies in the structure of the industry P85 average costs vector and in the structure of average revenues vector, as well. We can observe, for example, the distinctions in the intermediate purchases from the industry $\mathrm{N}$ (Administrative and support service activities). The sufficient differences between the relevant interindustry coefficients and allocation coefficients, and the relevant elements of the Leontief inverse and Ghosh inverse as well in corresponding industries explain the distinctions of value added creation power. Further investigation is needed together with industry P85 experts and must be oriented towards explaining the most essential differences between the line of indicators in order to elaborate adequate management decisions.

The main conclusions about feasibility of increasing value added of the Latvian industry P85 (Education) are the following: (a) economic input-output interactions between P85 and the rest national economy's industries and import structure as well allowed in principle the gross output growth and result value added growth, too. It means that the increasing of P85 gross output does not require respective changes in outputs of other industries to ensure an economic equilibrium; (b) it is crucially important for value added increasing in P85 to solve the sales revenues problem of the P85 final product. The most realistic way to attain an increase in value added of the industry P85 in Latvia is to encourage the export's revenue component of final demand. Some suggestions concerning P85 product export increasing are presented.

Note. All tables and all figures in the current paper are created by the author using NIOT data, mathematical models and Microsoft Excel tools.

\section{Materials and methods}

As mentioned in the introduction, the empirical material of the study is the National Input-Output Tables for the Period 2000-2014 (NIOT) available thanks to the World Input-Output Database (WIOD) with its unified structured statistical information in monetary terms (www.wiod.org). The main tool applied to identify the most important reasons, which cause the similarity and differences in the value added formation in the industry P85 in EST, FIN, LVA, LTU (in the sense of value added creation power), is the original version of the Input-Output model specifically constructed by the author [7] with regard to the given structured statistical information NIOT.

Let us shortly expound the theoretical input-output framework, key concepts, and methods used in connection with the structure of given NIOT information.

Let us assume that the open economy is categorized into $\mathrm{n}$ sectors (industries). The input-output price model based on monetary data in current prices is constructed by utilizing the national account's balancing equations. We consider the industry as the abstract subject-producer that holds the equilibrium balance: for each monetary unit produced the sum of purchasing expenditures (intermediate consumptions) plus value added equals the sum of sales revenues.

Let $i, j=1,2, \ldots, n$.

1 . The structure of the balancing equation

$$
d_{1 j}+d_{2 j}+\ldots+d_{n j}+m_{1 j}+m_{2 j}+\ldots+m_{n j}+v_{j}=1
$$

characterizes the input utilized for producing in the $\mathrm{j}$-th industry one monetary unit of total output. Here $d_{i j}$ is the domestic interindustry coefficient, $m_{i j}$ is the imported resources intermediate consumption coefficient, $v_{j}$ is the value added created by one monetary unit of total output in the $j$-th industry. The vector-column

$$
\left(D_{\cdot j}, M_{\cdot j}, v_{j}\right):=\left(d_{1 j}, d_{2 j}, \ldots, d_{n j}, m_{1 j}, m_{2 j}, \ldots, m_{n j}, v_{j}\right)^{T} \in R^{n+n+1,1}
$$

shows the average production costs for producing one monetary unit of output, and value added created withal. The vector $\left(D_{\cdot_{j}}, M_{\cdot_{j}}, v_{j}\right)$ indicates the purchasing structure of $j$-th industry in order to 
produce one monetary unit of gross output. This vector is determined by technological standards and specifications of $j$-th industry and domestic economy capacity. In this paper we mostly do not make the difference - are the resources utilized domestic or imported, we are interested only in average costs of product. Let us call the vector

$$
A_{\cdot_{j}}:=D_{\cdot_{j}}+M_{\cdot_{j}}
$$

as technology of $j$-th industry. The matrix

$$
A:=\left(A \cdot{ }_{1} A \cdot 2 \ldots A \cdot{ }_{\cdot n}\right) \in R^{n, n}
$$

is called the technology matrix of the given national economy.

2. The structure of the balancing equation

$$
g_{j 1}+g_{j 2}+\ldots+g_{j n}+w_{j}=1,
$$

characterizes utilizing the monetary unit of the $j$-th industry output as domestic allocation coefficients and final demand. Here $g_{j k}$ is the domestic allocation coefficient - the part of $j$-th industry monetary unit sold to the $k$-th industry, $w_{j}$ is the part of $j$-th industry monetary unit industry sold to the final consumers. The most important parts of the final demand $w_{j}$ are the CONS_h (Final consumption expenditure by households), CONS_g (Final consumption expenditure by government), EXP (Exports), GFCF (Gross fixed capital formation), CONS_np (Final consumption expenditure by nonprofit organisations serving households). Let us interpret the vector-row

$$
\left(G_{j} ., w_{j}\right):=\left(g_{j 1}, g_{j 2}, \ldots, g_{j n}, w_{j}\right) \in R^{1, n+1}
$$

as sales revenue vector of one monetary unit made from the $\mathrm{j}$-th industry.

Note 1. It should be emphasised that each industry as the subject-producer holds the equilibrium balance - for each monetary unit produced the sum of purchasing expenditures equals the sum of sales revenues:

$$
a_{1 j}+a_{2 j}+\ldots+a_{n j}+v_{j}=g_{j 1}+g_{j 2}+\ldots+g_{j n}+w_{j}=1 \text {. }
$$

It is well-known that in market economy it is easy to buy and difficult to sell. Economists are more concerned about chances to get revenue $g_{j 1}+g_{j 2}+\ldots+g_{j n}+w_{j}$ than about the perspectives of purchases $a_{1 j}+a_{2 j}+\ldots+a_{n j}$. Better sales conditions ensure the bigger sum $g_{j 1}+g_{j 2}+\ldots+g_{j n}+w_{j}$, but the better purchasing conditions and more efficient production technology ensure the smaller sum $a_{1 j}+a_{2 j}+\ldots+a_{n j}$. As a result the industry receives the bigger value added $v_{j}$ with respect to the monetary unit of output.

Note 2. The sum $d_{1 j}+d_{2 j}+\ldots+d_{n j}$ is called the direct backward linkage of $j$-th industry with respect to the domestic economy (DBL_domestic); the sum $m_{1 j}+m_{2 j}+\ldots+m_{n j}$ is called the direct backward linkage of $j$-th industry with respect to the import (DBL_import); the sum $a_{1 j}+a_{2 j}+\ldots+a_{n j}$ is called the direct backward linkage of $j$-th industry (DBL); the sum $g_{j 1}+g_{j 2}+\ldots+g_{j n}$ is called the direct forward linkage of $j$-th industry (DFL).

3. The vector-column

$$
\Lambda_{\cdot j}=:\left(\lambda_{1 j}, \lambda_{2 j}, \ldots, \lambda_{n j}\right)^{T} \in R^{n, 1},
$$

where $\lambda_{i j}$ is the element of the Leontief inverse matrix $\Lambda:=(I-D)^{-1}$, reflects the required balanced growth of all $\mathrm{n}$ domestic industries outputs to ensure increased final product of the $j$-th industry by one monetary unit when all other industries' final products remain unchanged.

The vector-column

$$
(M \Lambda)_{{ }_{j}}=:\left(\mu_{1 j}, \mu_{2 j}, \ldots, \mu_{n j}\right)^{T} \in R^{n, 1},
$$

where $\mu_{i j}$ is the element of transformed import matrix $M \Lambda$, reflects the required growth of all $\mathrm{n}$ imported products to ensure the balanced increasing of the final $j$-th product by one monetary unit when all other industries' final products remain unchanged.

\section{The vector-row}

$$
\Gamma_{j} .:=\left(\gamma_{j 1}, \gamma_{j 2}, \ldots, \gamma_{j n}\right) \in R^{1, n},
$$


where $\gamma_{i j}$ is the element of the Ghosh inverse matrix $\Gamma:=(I-G)^{-1}$, reflects the required balanced growth of all $\mathrm{n}$ domestic industries outputs to ensure the balanced $j$-th industry's value added increasing by one monetary unit when all other industries' added values remain unchanged.

Note 3 . The vectors $\Lambda_{{ }_{j}},(M \Lambda)_{{ }_{j}}$ are very useful for our analysis, because they describe the necessary increase in domestic output and import to provide the balanced increasing of the $j$-th final product by one monetary unit when all other industries' added values remain unchanged. Such information allows us to estimate the likelihood of a j-th final product increase. For instance, if impact on domestic output or ton the import from such action is unrealistically big, than action is not real. If impact is relatively small, than we have to study the sales problem: how to ensure the balance

$$
a_{1 j}+a_{2 j}+\ldots+a_{n j}+v_{j}=g_{j 1}+g_{j 2}+\ldots+g_{j n}+w_{j}=1 .
$$

Note 4. The sum $\lambda_{1 j}+\lambda_{2 j}+\ldots+\lambda_{n j}$ is called the total backward linkage of $j$-th industry to the domestic economy (TBL); the sum $\mu_{1 j}+\mu_{2 j}+\ldots+\mu_{n j}$ is called the total backward linkage of $j$-th industry to the import (TBL_import); the sum $\gamma_{j 1}+\gamma_{j 2}+\ldots+\gamma_{j n}$ is called the total forward linkage of $j$-th industry to the domestic economy (TFL).

Note 5. Shortly about the concept of value added in microeconomics, macroeconomics and in the WIOD. In microeconomics an acceptable definition of firm's created value added is given in the book Economics by Äke Blomqvist, Paul Wonnacott, Ronald Wonnacott [5]: "Value added. Value of the product sold less the cost of intermediate products bought from other firms". The macroeconomic concept of value added created by an industry is explained in the European Central Bank (ECB) Glossary [7]: "value added (gross) is total output less the intermediate consumption". Eurostat definition [8;9]: "GDP = compensation of employees + gross operating surplus + net taxes on production and imports." The Input-Output model exposes the holistic logic of the definitions given by the ECB and Eurostat.

It should also be critically remarked that WIOD does not explore the structure of value added, which is a substantial deficiency, because it makes impossible to investigate the distribution of created wealth between different economic agents.

Example.

To be reader friendly, let us use a simplified model borrowed from the famous book Input-Output Economics by Wassily Leontief [1]. According to our studies the author has transformed this example from a closed economy to an open economy situation to have a data structure similar to the structure of NIOT. The author appeals to colleagues to provide themselves the proper calculations in order to check correctness of all tables and equations below.

The input-output data for two industries as direct and dual balances in the monetary terms are given (Table 1).

Table 1

\section{Leontief's' input-output example in monetary terms}

\begin{tabular}{|l|c|c|c|c|c|}
\hline & & agriculture & production & final product & total output \\
\hline agriculture & domestic & 50 & 40 & 145 & 230 \\
\hline production & domestic & 70 & 30 & 150 & 300 \\
\hline agriculture & imports & 20 & 15 & & \\
\hline production & imports & 10 & 35 & & \\
\hline primary factor & & 80 & 180 & & \\
\hline total output & & 230 & 300 & & \\
\hline
\end{tabular}

By using the data in Table 1 , we obtain the $(2 \times 2)$-matrix of domestic interindustry coefficients denoted as $\mathrm{D}$ and the $(2 \times 2)$-matrix of imported interindustry coefficients denoted as $M$, values added $v_{1}, v_{2}$ (Table 2).

For instance, the vector-column

$$
\left(D \cdot{ }_{1}, M_{\cdot 1}, v_{1}\right):=(0.2174 ; 0.3043 ; 0.0870 ; 0.0435 ; 0.3478)^{T} \in R^{2+2+1,1}
$$

shows the average production costs for producing one monetary unit of output and value added created withal in agriculture. 
The technology of agriculture describes the vector

$$
A \cdot{ }_{1}:=D \cdot{ }_{1}+M \cdot{ }_{1}=(0.3043 ; 0.3478)^{T} \in R^{2,1} .
$$

Table 3 contains allocations coefficients and final demand coefficients.

Table 2

Matrix D, matrix M, values added $v_{1}, v_{2}$

\begin{tabular}{|l|c|c|c|}
\hline & & agriculture & production \\
\hline agriculture & domestic & 0.2174 & 0.1333 \\
\hline production & domestic & 0.3043 & 0.1000 \\
\hline agriculture & imports & 0.0870 & 0.0500 \\
\hline production & imports & 0.0435 & 0.1167 \\
\hline primary factor & & 0.3478 & 0.6000 \\
\hline total output & & 1 & 1 \\
\hline
\end{tabular}

Table 3

(2×2)-matrix G, final demands $w_{1}, w_{2}$

\begin{tabular}{|l|l|r|r|c|c|}
\hline & & agriculture & production & final demand & total \\
\hline agriculture & domestic & 0.2174 & 0.1739 & 0.6087 & 1 \\
\hline production & domestic & 0.2333 & 0.1000 & 0.6667 & 1 \\
\hline
\end{tabular}

The vector-row

$$
\left(G_{1},, w_{1}\right):=\left(g_{11}, g_{12}, w_{1}\right)=(0.2174 ; 0.1739 ; 0.6087) \in R^{1,2+1}
$$

is the sales revenue vector of one monetary unit made from agriculture.

The agriculture as the subject-producer must hold the balance - for each monetary unit produced the sum of purchasing expenditures must be equal the sum of sales revenues:

$$
0.3043+0.3478+0.3478=0.2174+0.1739+0.6087=1 .
$$

$(2 \times 2)$-Leotief inverse $\Lambda:=(I-D)^{-1}$, and proper $(2 \times 2)$-matrix $M \Lambda$

Table 4

\begin{tabular}{|l|c|c|c|}
\hline & & agriculture & production \\
\hline agriculture & domestic & 1.3559 & 0.2009 \\
\hline production & domestic & 0.4585 & 1.1790 \\
\hline agriculture & imports & 0.1408 & 0.0764 \\
\hline production & imports & 0.1124 & 0.1463 \\
\hline
\end{tabular}

Table 4 shows: for agriculture to be able to increase the final product by one monetary unit, when production industry's final product remains unchanged, the equilibrium of economy requires the total output increasing by vector $\Lambda \cdot_{1}=(1.3559 ; 0.4585)^{T}$ and import increasing by vector $(M \Lambda){ }_{{ }_{1}}=(0.1408$; $0.1124)^{T}$.

(2×2)-Gosh inverse $\Gamma:=(I-G)^{-1}$

Table 5

\begin{tabular}{|l|l|c|c|}
\hline & & agriculture & production \\
\hline agriculture & domestic & 1.3559 & 0.2620 \\
\hline production & domestic & 0.3515 & 1.1790 \\
\hline
\end{tabular}

Table 5 contains the Ghosh inverse. For instance, the vector-row $\Gamma_{1} \cdot=(1.3559 ; 0.2620)$ received from Table 5 reflects the required growth of both industries total outputs to ensure the value added increasing in agriculture by one monetary unit when value added in the production industry remains unchanged.

As mentioned in the introduction, the goal of the current study is to investigate what is the feasibility of the Latvian industry P85 (Education) to increase the value added. For this purpose an analysis of the Latvian industry P85 in terms of expenditures, revenues, and links to the national economy compared with Estonia, Lithuania and Finland will be carried out. After that the possibility of increasing the Latvian industry P85 final demand will be analysed. 
How could some analogy between the corresponding vectors $A_{{ }^{\prime} j}, G_{j} \cdot, \Lambda_{{ }^{\prime} j},(M \Lambda){ }_{{ }_{\cdot}}, \Gamma_{j}$. (where $j$ is the number of industry P85) in the Baltic States and Finland be identified?

We can observe that the most popular tool in the scientific publications is the correlation coefficient. A widespread opinion is that high correlation $\operatorname{corr}(X, Y)$ signalizes about an analogy between structure of the multi-dimensional vectors $X$ and $Y$. In this paper as quantitative coincidence indicator of level of analogy the angle between vectors $X, Y$ is offered. If the angle between vectors $X$ and $Y$ is narrow (say, angle $(X, Y) \in\left[0^{\circ} ; 10^{\circ}\right]$ ), then also correlation between $X$ and $Y$ is high. At the same time, the high correlation between $X$ and $Y$ does not guarantee a narrow angle between $X$ and $Y$. Explanation of this assessment is simple, namely, the correlation coefficient $\operatorname{corr}(X, Y)$ equals cosine from the angle between vector $Y$ and projection of $Y$ to the two-dimensional subspace $\operatorname{lin}\{X, I\}$, where I is correspondingly dimensional vector all components of what equals 1 . Let us observe it with help of a simple example. In Table 6 four vectors $X, Y, Z . I \in R^{6}$ are presented. Calculations show that $\operatorname{corr}(X, Y)=0.9985 ; \operatorname{angle}(X, Y)=2^{\circ}$. $\operatorname{corr}(X, Z)=1$, because of $Z=0.01 X+0.50 \mathrm{I}$, but in the same time angle $(X, Z)=38^{\circ}$. Everybody agrees that $X$ and $Y$ have highly analogical structure, but analogy between the vectors $\mathrm{X}$ and $\mathrm{Z}$ is spoiled trough the item $0.50 \mathrm{I}$.

As vectors' $X, Y$ coincidence indicator also the coefficient $\mathrm{k}$ in the expression "[projection $Y$ to $X]=k X^{\prime \prime}$ is used.

Vectors X, Y, Z, I in Eucledian space $\mathbf{R}^{6}$

Table 6

\begin{tabular}{|c|c|c|c|c|c|c|}
\hline $\mathrm{X}$ & 0.03000 & 0.00900 & 0.06000 & 0.07000 & 0.00400 & 0.02000 \\
\hline $\mathrm{Y}$ & 0.03260 & 0.00972 & 0.06000 & 0.06800 & 0.00362 & 0.02200 \\
\hline $\mathrm{Z}$ & 0.50030 & 0.50009 & 0.50060 & 0.50070 & 0.50004 & 0.50020 \\
\hline $\mathrm{I}$ & 1 & 1 & 1 & 1 & 1 & 1 \\
\hline
\end{tabular}

Resume. Therefore, the main objects that have to be investigated in order to characterize $j$-th industry are:

(1) The vector $\left(D_{\cdot_{j}}, M_{\cdot j}, v_{j}\right) \in R^{n+n+1,1}$ that indicates the purchasing structure of $j$-th industry in order to sell one monetary unit of gross output. The vector $A_{{ }^{\prime} j}:=D_{{ }_{\cdot j}}+M_{{ }_{\cdot j}} \in R^{n, 1}$ as technology of $j$-th industry.

(2) The vector $\left(G_{j} ., w_{j}\right) \in R^{1, n+1}$ as the sales revenue vector of one monetary unit made from the $\mathrm{j}$-th industry. Industry holds the equilibrium balance - for each monetary unit produced the sum of purchasing expenditures equals the sum of sales revenues.

(3) The vector $\Lambda_{\cdot j} \in R^{n, 1}$ reflects the required balanced growth of all $\mathrm{n}$ industries outputs to ensure an increasing final product of the $\mathrm{j}$-th industry by one monetary unit when all other industries' final products remain unchanged. The vector $(M \Lambda)_{{ }_{j}} \in R^{n, 1}$ reflects the required growth of all $\mathrm{n}$ imported products to ensure the balanced increasing the final $j$-th product by one monetary unit when all other industries' final products remain unchanged.

(4) The vector $\Gamma_{j}, \in R^{1, n}$ reflects the required balanced growth of all $\mathrm{n}$ industries outputs to ensure the balanced $j$-th industry's value added increase by one monetary unit when all other industries' added values remain unchanged.

\section{Results and discussion}

The inward logic and consistency of the research are the following.

The industry's P85 value added increase can be attained: (a) as a result of gross output increase or (b) as a result of average cost (input) with respect to monetary unit of output decreasing.

The materials and methods examined before allow us to investigate conditions (a) and (b) in the Latvian case. In order to get a complete view on the industry's P85 behaviour in EST, FIN, LVA, LTU the line of indicators is calculated. It should be emphasised that interpretations of indicators used are based on holistic mathematical connections resulted from the input-output model as a whole.

The solution (a) is possible, if: (a1) the gross output increase in P85 does not require through interindustry links unrealistic increasing of the rest of national economy; (a2) it is possible to expand sufficiently the final demand of P85 product. 
The solution (b) is possible, if industry's P85 management in Latvia is able to adopt better controlling patterns from foreign countries.

The economic analysis leads to the main conclusion: the most realistic tool to increase value added in the Latvian P85 is the well-organized marketing in order to expand the higher education exports because of final demand increasing in P85 does not require exorbitant conditions to the rest national economy, but at the same time leads directly to an increase in value added.

Note. It is handy to use the code of industries in the text. For reader's convenience the code and descriptions used in NIOT are given in Table 7. Since industries in NIOT according to the International Standard Industrial Classification are strongly defined and international, the author appeals to colleagues to employ the NIOT codes on a regular basis for more unified and precise scientific understanding of the notion of each industry.

Table 7

NIOT industries' codes and descriptions

\begin{tabular}{|c|c|}
\hline Code & Description \\
\hline A01 & Crop and animal production, hunting and related service activities \\
\hline A02 & Forestry and logging \\
\hline A03 & Fishing and aquaculture \\
\hline $\mathrm{B}$ & Mining and quarrying \\
\hline $\mathrm{C} 10-\mathrm{C} 12$ & Manufacture of food products, beverages and tobacco products \\
\hline $\mathrm{C} 13-\mathrm{C} 15$ & Manufacture of textiles, wearing apparel and leather products \\
\hline $\mathrm{C} 16$ & $\begin{array}{l}\text { Manufacture of wood and of products of wood and cork, except furniture; manufacture of } \\
\text { articles of straw and plaiting materials }\end{array}$ \\
\hline $\mathrm{C} 17$ & Manufacture of paper and paper products \\
\hline $\mathrm{C} 18$ & Printing and reproduction of recorded media \\
\hline $\mathrm{C} 19$ & Manufacture of coke and refined petroleum products \\
\hline $\mathrm{C} 20$ & Manufacture of chemicals and chemical products \\
\hline $\mathrm{C} 21$ & Manufacture of basic pharmaceutical products and pharmaceutical preparations \\
\hline $\mathrm{C} 22$ & Manufacture of rubber and plastic products \\
\hline $\mathrm{C} 23$ & Manufacture of other non-metallic mineral products \\
\hline $\mathrm{C} 24$ & Manufacture of basic metals \\
\hline $\mathrm{C} 25$ & Manufacture of fabricated metal products, except machinery and equipment \\
\hline $\mathrm{C} 26$ & Manufacture of computer, electronic and optical products \\
\hline $\mathrm{C} 27$ & Manufacture of electrical equipment \\
\hline $\mathrm{C} 28$ & Manufacture of machinery and equipment n.e.c. \\
\hline $\mathrm{C} 29$ & Manufacture of motor vehicles, trailers and semi-trailers \\
\hline $\mathrm{C} 30$ & Manufacture of other transport equipment \\
\hline C31_C32 & Manufacture of furniture; other manufacturing \\
\hline $\mathrm{C} 33$ & Repair and installation of machinery and equipment \\
\hline D35 & Electricity, gas, steam and air conditioning supply \\
\hline E36 & Water collection, treatment and supply \\
\hline E37-E39 & $\begin{array}{l}\text { Sewerage; waste collection, treatment and disposal activities; materials recovery; remediation } \\
\text { activities and other waste management services }\end{array}$ \\
\hline $\mathrm{F}$ & Construction \\
\hline G45 & Wholesale and retail trade and repair of motor vehicles and motorcycles \\
\hline G46 & Wholesale trade, except of motor vehicles and motorcycles \\
\hline G47 & Retail trade, except of motor vehicles and motorcycles \\
\hline $\mathrm{H} 49$ & Land transport and transport via pipelines \\
\hline $\mathrm{H} 50$ & Water transport \\
\hline H51 & Air transport \\
\hline H52 & Warehousing and support activities for transportation \\
\hline H53 & Postal and courier activities \\
\hline $\mathrm{I}$ & Accommodation and food service activities \\
\hline J58 & Publishing activities \\
\hline J59_J60 & $\begin{array}{l}\text { Motion picture, video and television programme production, sound recording and music } \\
\text { publishing activities; programming and broadcasting activities }\end{array}$ \\
\hline J61 & Telecommunications \\
\hline
\end{tabular}


Table 7 (continued)

\begin{tabular}{|l|l|}
\hline Code & Description \\
\hline J62_J63 & Computer programming, consultancy and related activities; information service activities \\
\hline K64 & Financial service activities, except insurance and pension funding \\
\hline K65 & Insurance, reinsurance and pension funding, except compulsory social security \\
\hline K66 & Activities auxiliary to financial services and insurance activities \\
\hline L68 & Real estate activities \\
\hline M69_M70 & Legal and accounting activities; activities of head offices; management consultancy activities \\
\hline M71 & Architectural and engineering activities; technical testing and analysis \\
\hline M72 & Scientific research and development \\
\hline M73 & Advertising and market research \\
\hline M74_M75 & Other professional, scientific and technical activities; veterinary activities \\
\hline N & Administrative and support service activities \\
\hline O84 & Public administration and defence; compulsory social security \\
\hline P85 & Education \\
\hline Q & Human health and social work activities \\
\hline R_S & Other service activities \\
\hline
\end{tabular}

1. Excerpts from the NIOT 2014 concerning industry's P85 expenditures and revenues in current prices, expressed in millions of US dollars.

Tables 8 and 9 contain the general indicators that describe P85 intermediate consumption. Tables 10 and 11 contain main allocation coefficients.

Industry's P85 expenditures in EST, FIN, LVA, LTU

Table 8

\begin{tabular}{|c|c|c|c|c|c|}
\hline Code & Description & EST & FIN & LVA & LTU \\
\hline & Intermediate consumption (domestic) & 291.23 & 4082.51 & 314.93 & 258.86 \\
\hline & Intermediate consumption (imports) & 87.96 & 494.73 & 93.37 & 190.91 \\
\hline II_fob & Total intermediate consumption & 379.19 & 4577.24 & 408.30 & 449.77 \\
\hline GVA & Gross value added at basic prices & 1090.91 & 14072.24 & 1384.49 & 2035.54 \\
\hline VA & Net value added at basic prices & 1062.11 & 13536.09 & 1367.66 & 1994.97 \\
\hline GO & Output at basic prices & 1470.10 & 18649.48 & 1792.79 & 2485.31 \\
\hline
\end{tabular}

Table 9

Industry's P85 expenditures in EST, FIN, LVA, LTU with respect to monetary unit of output

\begin{tabular}{|c|c|c|c|c|c|}
\hline Code & Description & EST & FIN & LVA & LTU \\
\hline & Intermediate consumption (domestic) & 0.1981 & 0.2189 & 0.1757 & 0.1042 \\
\hline & Intermediate consumption (imports) & 0.0598 & 0.0265 & 0.0521 & 0.0768 \\
\hline II_fob & Total intermediate consumption & 0.2579 & 0.2454 & 0.2277 & 0.1810 \\
\hline GVA & Gross value added at basic prices & 0.7421 & 0.7546 & 0.7723 & 0.8190 \\
\hline VA & Net value added at basic prices & 0.7225 & 0.7258 & 0.7629 & 0.8027 \\
\hline GO & Output at basic prices & 1 & 1 & 1 & 1 \\
\hline
\end{tabular}

Industry's P85 final demand in EST, FIN, LVA, LTU

\begin{tabular}{|c|c|c|c|c|c|c|c|c|}
\hline Code & Intermediate sales & CONS_h & CONS_np & CONS_g & GFCF & INVEN & EXP & GO \\
\hline EST & 82.47 & 155.67 & 25.54 & 1191.61 & 6.95 & 0.03 & 7.69 & 1470.10 \\
\hline FIN & 1526.24 & 773.52 & 1309.64 & 13553.43 & 884.12 & -0.02 & 602.55 & 18649.48 \\
\hline LVA & 85.62 & 389.01 & 12.14 & 1237.76 & 59.52 & 0.01 & 8.87 & 1792.79 \\
\hline LTU & 95.15 & 305.55 & 0.00 & 1956.93 & 105.09 & 0.64 & 21.95 & 2485.31 \\
\hline
\end{tabular}

Code and Description:

CONS_h (Final consumption expenditure by households);

CONS_g (Final consumption expenditure by government);

CONS_np (Final consumption expenditure by non-profit organisations serving households (NPISH));

GFCF (Gross fixed capital formation); INVEN (Changes in inventories and valuables);

EXP (Exports); GO (Gross output). 
Table 11

Industry's P85 final demand in EST, FIN, LVA, LTU with respect to monetary unit of output

\begin{tabular}{|c|c|c|c|c|c|c|c|c|}
\hline Code & Intermediate sales & CONS_h & CONS_np & CONS_g & GFCF & INVEN & EXP & GO \\
\hline EST & 0.0561 & 0.1059 & 0.0174 & 0.8106 & 0.0047 & 0.0000 & 0.0052 & 1 \\
\hline FIN & 0.0818 & 0.0415 & 0.0702 & 0.7267 & 0.0474 & 0.0000 & 0.0323 & 1 \\
\hline LVA & 0.0478 & 0.2170 & 0.0068 & 0.6904 & 0.0332 & 0.0000 & 0.0049 & 1 \\
\hline LTU & 0.0383 & 0.1229 & 0.0000 & 0.7874 & 0.0423 & 0.0003 & 0.0088 & 1 \\
\hline
\end{tabular}

The relationships between the contents of Tables 9 and 11 show that in EST, FIN, LVA, LTU value added in P85 almost completely consists of government purchases, but the role of exports is misery (Table 12, Figure 1).

Industry's P85 value added formations: role of government and exports

\begin{tabular}{|l|c|c|c|c|}
\hline & EST & FIN & LVA & LTU \\
\hline VA/CONS_g & 0.89 & 1.00 & 1.10 & 1.02 \\
\hline EXP/VA & 0.0072 & 0.0445 & 0.0065 & 0.0110 \\
\hline
\end{tabular}

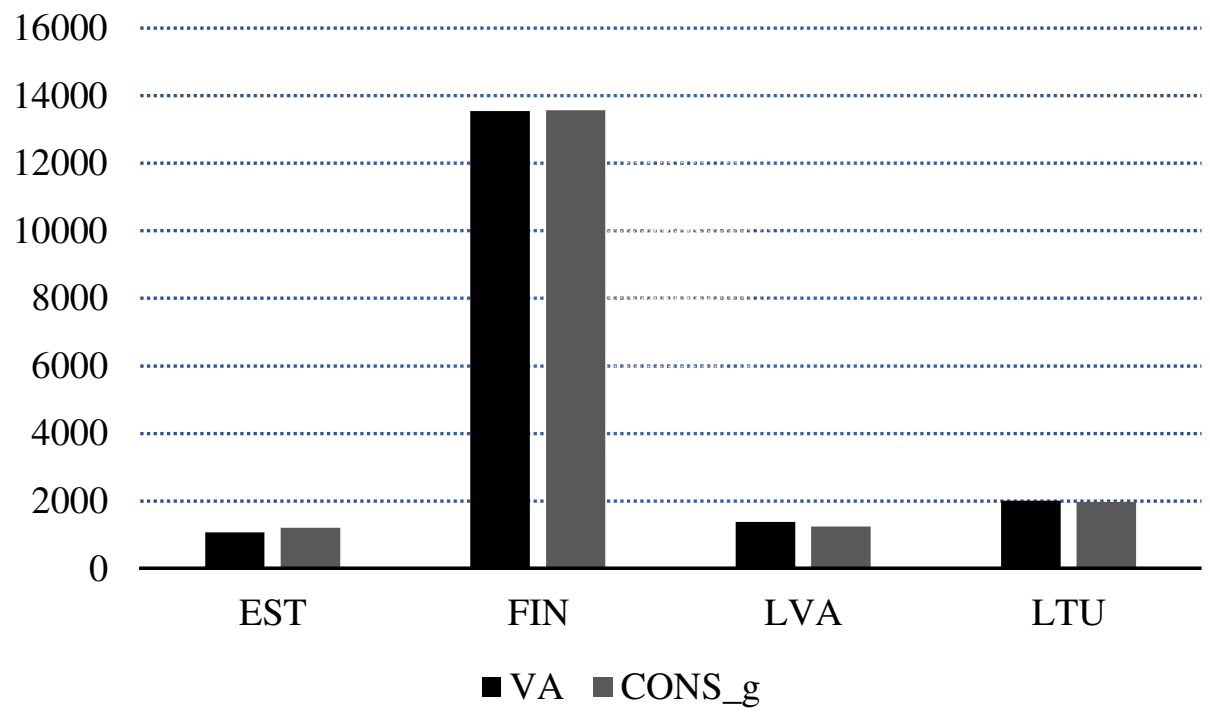

Fig. 1. Industry's P85 value added and final consumption expenditure by government

As vectors' $X, Y$ coincidence indicators the angle between vectors $X, Y$ and coefficient $\mathrm{k}$ in the expression "[projection $Y$ to $X$ ] $=k X$ " are used. In Table 13 coincidence indicators of final demand are presented. Angle $3.30^{\circ}$ shows that vectors of final demand for EST and LTU are most similar. Generally speaking, the structure of final demand is relatively similar in all examined countries: $70 \%$ or more refers to the CONS_g (Final consumption expenditure by government). As to the exports, only FIN has $3 \%$, but EST, LVA, LTU have less than $1 \%$. It is worth to investigate Finland's $7 \%$ supported by CONS_np (Final consumption expenditure by non-profit organisations serving households (NPISH)). Estonia with $1.7 \%$ tries to follow FIN, but LVA, LTU practically do not utilize demand of CONS_np.

Table 13

Matrix of coincidence indicators of final demand with respect to monetary unit of output

\begin{tabular}{|c|c|c|c|}
\hline angle & FIN & LVA & LTU \\
\hline EST & $7.20^{\circ}$ & $10.28^{\circ}$ & $3.30^{\circ}$ \\
\hline FIN & & $15.17^{\circ}$ & $8.09^{\circ}$ \\
\hline LVA & & & $8.59^{\circ}$ \\
\hline coeff & FIN & LVA & LTU \\
\hline EST & 0.89 & 0.78 & 0.14 \\
\hline FIN & & 0.53 & 0.08 \\
\hline LVA & & & 0.10 \\
\hline
\end{tabular}


2. Comparison and analysis of total intermediate consumption.

Table 14 contains two arranged (from largest to smallest) excerpts from the total intermediate consumption matrix A: arrangement by LVA indicators and arrangement by FIN indicators. We can observe total distinction in the ten biggest total intermediate consumptions (domestic plus imported purchases) per monetary unit of total output. Explanation of such difference requires further investigations.

Table 14

Industry's P85 seven biggest input indicators in LVA and FIN (components of the vectors $A_{j j}:=D_{{ }_{j}}+M_{{ }_{j}}$ )

\begin{tabular}{|c|c|c|c|c|}
\hline Code & EST & FIN & LVA & LTU \\
\hline D35 & 0.0355 & 0.0120 & $\mathbf{0 . 0 4 8 6}$ & 0.0097 \\
\hline N & 0.0157 & 0.0174 & $\mathbf{0 . 0 2 9 4}$ & 0.0012 \\
\hline F & 0.0090 & 0.0088 & $\mathbf{0 . 0 1 8 5}$ & 0.0144 \\
\hline L68 & 0.0211 & 0.0342 & $\mathbf{0 . 0 1 1 6}$ & 0.0026 \\
\hline C10_C12 & 0.0140 & 0.0054 & $\mathbf{0 . 0 1 0 6}$ & 0.0012 \\
\hline P85 & 0.0140 & 0.0169 & $\mathbf{0 . 0 1 0 0}$ & 0.0063 \\
\hline C20 & 0.0038 & 0.0011 & $\mathbf{0 . 0 0 9 9}$ & 0.0013 \\
\hline DBL & 0.2580 & 0.2454 & 0.2277 & 0.1810 \\
\hline
\end{tabular}

\begin{tabular}{|c|c|c|c|c|}
\hline Code & EST & FIN & LVA & LTU \\
\hline L68 & 0.0211 & $\mathbf{0 . 0 3 4 2}$ & 0.0116 & 0.0026 \\
\hline I & 0.0183 & $\mathbf{0 . 0 1 8 9}$ & 0.0038 & 0.0012 \\
\hline N & 0.0157 & $\mathbf{0 . 0 1 7 4}$ & 0.0294 & 0.0012 \\
\hline P85 & 0.0140 & $\mathbf{0 . 0 1 6 9}$ & 0.0100 & 0.0063 \\
\hline H49 & 0.0162 & $\mathbf{0 . 0 1 5 2}$ & 0.0046 & 0.0006 \\
\hline J62_J63 & 0.0052 & $\mathbf{0 . 0 1 2 1}$ & 0.0024 & 0.0015 \\
\hline D35 & 0.0355 & $\mathbf{0 . 0 1 2 0}$ & 0.0486 & 0.0097 \\
\hline
\end{tabular}

We observe sufficient differences in the intermediate consumption ranks in these four countries. For example, in LVA intermediate product cost of the industry D35 (Electricity, gas, steam and air conditioning supply) is 0.048 with respect to one monetary unit of gross output. At the same time, in FIN this indicator equals 0.0120 that indicates the thrift of D35 product in LVA. Concerning the intermediate product consumption of L68 (Real estate activities), the situation is antipodal: in FIN it is 0.0342 , while in LVA it is 0.0116 .

The author considers that it is typical for LVA to have exaggerated administrative (N) costs (Figure 2).



Fig. 2. Administrative and support service activities $(\mathbf{N})$ related to monetary unit of gross output (GO) in P85

In Table 15 coincidence indicators are presented. Angle $31.96^{\circ}$ shows that vectors of intermediate consumption for EST and LVA are the most similar ones. Coefficient 0.78 means that "[projection $A{ }_{\cdot j}$

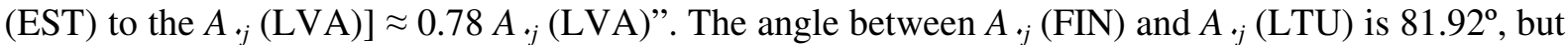
"[projection $A_{{ } j}(\mathrm{FIN})$ to the $\left.A_{{ }^{\prime} j}(\mathrm{LTU})\right] \approx 0.08 A_{{ }^{\prime} j}(\mathrm{LTU})$ ". This indicates sufficient differences in the intermediate consumption structure. The angle between $A_{{ }^{\prime} j}(\mathrm{FIN})$ and $A_{{ }^{\prime}}$ (LVA) is $51.97^{\circ}$, but "[projection $A_{{ }^{\prime} j}(\mathrm{FIN})$ to the $\left.A_{{ }^{\prime} j}(\mathrm{LVA})\right] \approx 0.53 A_{{ }^{\prime} j}$ (LTU)".

Of course, it would be useful to undertake a rigorous analysis of the Latvian P85 total intermediate consumption increase compared with the better experience in EST, FIN, LTU conducted together with experts.

For all that, reduction of the total intermediate consumption costs is not a topical problem right now, because the total intermediate consumption with respect to monetary unit of gross output in LVA is $22.8 \%$, in EST this indicator equals $25.8 \%$, in FIN $-24.5 \%$, in LTU $-18.1 \%$. 
Matrix of coincidence indicators of intermediate consumption vectors $A_{{ }_{j}}$

Table 15

\begin{tabular}{|c|c|c|c|}
\hline angle & FIN & LVA & LTU \\
\hline EST & $33.09^{\circ}$ & $31.96^{\circ}$ & $76.32^{\circ}$ \\
\hline FIN & & $51.97^{\circ}$ & $81.92^{\circ}$ \\
\hline LVA & & & $80.93^{\circ}$ \\
\hline coeff & FIN & LVA & LTU \\
\hline EST & 0.89 & 0.78 & 0.14 \\
\hline FIN & & 0.53 & 0.08 \\
\hline LVA & & & 0.10 \\
\hline
\end{tabular}

3. Comparison and analysis of allocation coefficients.

Table 16 contains two arranged (from largest to smallest) excerpts from the allocation matrices $G$ : arrangement by LVA indicators and arrangement by FIN indicators. We can observe total distinction in the ten biggest buyers of P85 product. Explanation of such difference requires further investigations.

Table 16

Industry's P85 ten biggest allocations coefficients for LVA and FIN (components of the vectors $G_{j}$.)

\begin{tabular}{|c|c|c|c|c|c|c|c|c|c|c|}
\hline & P85 & J62_J63 & F & G46 & M69_M70 & G47 & N & H52 & H51 & K64 \\
\hline EST & 0.0112 & 0.0017 & 0.0013 & 0.0014 & 0.0008 & 0.0019 & 0.0014 & 0.0012 & 0.0007 & 0.0021 \\
\hline FIN & 0.0166 & 0.0043 & 0.0004 & 0.0013 & 0.0019 & 0.0023 & 0.0005 & 0.0001 & 0.0001 & 0.0005 \\
\hline LVA & $\mathbf{0 . 0 0 9 5}$ & $\mathbf{0 . 0 0 8 6}$ & $\mathbf{0 . 0 0 4 1}$ & $\mathbf{0 . 0 0 3 9}$ & $\mathbf{0 . 0 0 2 9}$ & $\mathbf{0 . 0 0 2 6}$ & $\mathbf{0 . 0 0 2 0}$ & $\mathbf{0 . 0 0 1 9}$ & $\mathbf{0 . 0 0 1 0}$ & $\mathbf{0 . 0 0 0 9}$ \\
\hline LTU & 0.0062 & 0.0004 & 0.0009 & 0.0010 & 0.0007 & 0.0050 & 0.0005 & 0.0015 & 0.0000 & 0.0035 \\
\hline
\end{tabular}

\begin{tabular}{|c|c|c|c|c|c|c|c|c|c|c|}
\hline & P85 & C26 & O84 & Q & R_S & J62_J63 & G47 & M69_M70 & G46 & J58 \\
\hline EST & 0.0112 & 0.0007 & 0.0103 & 0.0018 & 0.0035 & 0.0017 & 0.0019 & 0.0008 & 0.0014 & 0.0003 \\
\hline FIN & $\mathbf{0 . 0 1 6 6}$ & $\mathbf{0 . 0 1 5 0}$ & $\mathbf{0 . 0 1 0 3}$ & $\mathbf{0 . 0 0 9 9}$ & $\mathbf{0 . 0 0 9 6}$ & $\mathbf{0 . 0 0 4 3}$ & $\mathbf{0 . 0 0 2 3}$ & $\mathbf{0 . 0 0 1 9}$ & $\mathbf{0 . 0 0 1 3}$ & $\mathbf{0 . 0 0 1 2}$ \\
\hline LVA & 0.0095 & 0.0000 & 0.0001 & 0.0005 & 0.0006 & 0.0086 & 0.0026 & 0.0029 & 0.0039 & 0.0002 \\
\hline LTU & 0.0062 & 0.0000 & 0.0016 & 0.0092 & 0.0007 & 0.0004 & 0.0050 & 0.0007 & 0.0010 & 0.0001 \\
\hline
\end{tabular}

In Table 17 coincidence indicators are presented.

Angle $39^{\circ}$ shows that vectors of allocation coefficients for EST and FIN are the most similar ones. Coefficient 0.45 means that "[projection $G_{j}$. (EST) to the $G_{j}$. (FIN] $\approx 0.45 G_{j}$. (FIN)". The angle between $G_{j}$. (LVA) and $G_{j}$.(LTU) is $60.31^{\circ}$, but "[projection $G_{j}$.(LVA) to the $G_{j}$.(LTU)] $\approx 0.56 G_{j}$. (LTU)". That indicates a sufficient difference in the structure of P85 product allocation. The angle between $G_{j}$. (FIN) and $G_{j}$. (LVA) is $57.96^{\circ}$, but "[projection $G_{j}$. (FIN) to the $G_{j}$. (LVA)] $\approx 1.02 G_{j}$. (LVA)".

Of course, a rigorous analysis of the Latvian P85 product allocation in the national economy compared with EST, FIN, LTU would be useful. For all that, the P85 product allocation towards the rest national industries is not a topical problem right now, because the direct forward linkage in LVA is $4.8 \%$, in EST this indicator equals $5.6 \%$, in FIN - 8.2 \%, in LTU - 3.8 \%.

Table 17

Matrix of coincidence indicators of allocation vectors $\boldsymbol{G}_{j}$.

\begin{tabular}{|c|c|c|c|}
\hline angle & FIN & LVA & LTU \\
\hline EST & $38.99^{\circ}$ & $51.36^{\circ}$ & $54.01^{\circ}$ \\
\hline FIN & & $57.96^{\circ}$ & $52.26^{\circ}$ \\
\hline LVA & & & $60.31^{\circ}$ \\
\hline coeff & FIN & LVA & LTU $^{\circ}$ \\
\hline EST & 0.45 & 0.70 & 0.74 \\
\hline FIN & & 1.02 & 1.32 \\
\hline LVA & & & 0.56 \\
\hline
\end{tabular}


4. Comparison and analysis of the impact of P85 final demand increase on the total output required for equilibrium in the national economy.

Table 18 contains two arranged (from largest to smallest) excerpts from the Leontief inverse $\Lambda$ : arrangement by LVA indicators and arrangement by FIN indicators. We can observe sufficient distinction in the national industries' necessary reaction to the P85 final demand increase in order to provide economic equilibrium in the national economy.

Industry's P85 twelve biggest Leontief coefficients for LVA and FIN

Table 18 (components of the vectors $\Lambda_{j}$.)

\begin{tabular}{|c|c|c|c|c|}
\hline & EST & FIN & LVA & LTU \\
\hline P85 & 1.0117 & 1.0176 & $\mathbf{1 . 0 1 0 0}$ & 1.0063 \\
\hline D35 & 0.0310 & 0.0164 & $\mathbf{0 . 0 7 7 2}$ & 0.0103 \\
\hline F & 0.0043 & 0.0168 & $\mathbf{0 . 0 3 6 8}$ & 0.0079 \\
\hline N & 0.0183 & 0.0230 & $\mathbf{0 . 0 3 5 6}$ & 0.0035 \\
\hline L68 & 0.0138 & 0.0432 & $\mathbf{0 . 0 1 9 0}$ & 0.0028 \\
\hline G47 & 0.0127 & 0.0064 & $\mathbf{0 . 0 1 1 1}$ & 0.0012 \\
\hline H49 & 0.0130 & 0.0210 & $\mathbf{0 . 0 0 9 4}$ & 0.0007 \\
\hline G46 & 0.0029 & 0.0135 & $\mathbf{0 . 0 0 9 4}$ & 0.0027 \\
\hline H52 & 0.0048 & 0.0048 & $\mathbf{0 . 0 0 8 3}$ & 0.0018 \\
\hline J61 & 0.0092 & 0.0107 & $\mathbf{0 . 0 0 7 4}$ & 0.0064 \\
\hline C10-C12 & 0.0076 & 0.0125 & $\mathbf{0 . 0 0 6 7}$ & 0.0003 \\
\hline M69_M70 & 0.0104 & 0.0052 & $\mathbf{0 . 0 0 6 2}$ & 0.0071 \\
\hline TBL & 1.4742 & 1.3519 & $\mathbf{1 . 3 1 5 0}$ & 1.2260 \\
\hline
\end{tabular}

\begin{tabular}{|c|c|c|c|c|}
\hline & EST & FIN & LVA & LTU \\
\hline P85 & 1.0117 & $\mathbf{1 . 0 1 7 6}$ & 1.0100 & 1.0063 \\
\hline L68 & 0.0138 & $\mathbf{0 . 0 4 3 2}$ & 0.0190 & 0.0028 \\
\hline N & 0.0183 & $\mathbf{0 . 0 2 3 0}$ & 0.0356 & 0.0035 \\
\hline H49 & 0.0130 & $\mathbf{0 . 0 2 1 0}$ & 0.0094 & 0.0007 \\
\hline I & 0.0191 & $\mathbf{0 . 0 1 8 8}$ & 0.0045 & 0.0027 \\
\hline F & 0.0043 & $\mathbf{0 . 0 1 6 8}$ & 0.0368 & 0.0079 \\
\hline D35 & 0.0310 & $\mathbf{0 . 0 1 6 4}$ & 0.0772 & 0.0103 \\
\hline G46 & 0.0029 & $\mathbf{0 . 0 1 3 5}$ & 0.0094 & 0.0027 \\
\hline J62_J63 & 0.0088 & $\mathbf{0 . 0 1 2 6}$ & 0.0041 & 0.0037 \\
\hline C10-C12 & 0.0076 & $\mathbf{0 . 0 1 2 5}$ & 0.0067 & 0.0003 \\
\hline R_S & 0.0133 & $\mathbf{0 . 0 1 1 0}$ & 0.0036 & 0.0040 \\
\hline J61 & 0.0092 & $\mathbf{0 . 0 1 0 7}$ & 0.0074 & 0.0064 \\
\hline
\end{tabular}

Tables 18 and 19 show that in all considered countries - EST, FIN, LVA, LTU the industry P85 has to be qualified as an industry with low total backward linkage: TBL(EST_P85) $=1.47$; TBL $($ FIN_P85 $)=1.35$; TBL $($ LVA_P85 $)=1.32$; TBL $($ LTU_P85 $)=1.23$. It should be noted that more little TBL have only the industry Q (Human health and social work activities) and the industry M72 (Scientific research and development). That conclusion is important, because it indicates a relatively small impact on the rest national industries caused by an increase in the final demand in P85. Namely, if the industry P85 would be able to increase its final demand remaining all other industries final products unchanged, the required balanced growth of all rest national industries gross outputs in order to ensure economic equilibrium is not unrealistic and can be attained.

Table 19

LVA industries with twelve biggest total backward linkages (TBL) and industries

\begin{tabular}{|c|c|c|c|c|c|c|c|c|c|c|c|c|}
\hline \multicolumn{13}{|c|}{ with twelve smallest total backward linkag } \\
\hline ode & H52 & 19 & C16 & D35 & $\mathbf{F}$ & H51 & M73 & A02 & K65 & H49 & G46 & J58 \\
\hline TBL & 2.2395 & 2.2022 & 2.1677 & 2.0962 & 2.0953 & 2.0543 & 2.0234 & 1.9843 & 1.9606 & 1.8643 & 1.8290 & 1.8110 \\
\hline ode & J62_J63 & 084 & $\mathbf{C 2 9}$ & $\mathbf{C 2 8}$ & C17 & $\mathbf{C 2 2}$ & $\mathbf{C 2}$ & $\mathbf{C 2 5}$ & $\mathbf{C 2 6}$ & $\mathbf{P 8 5}$ & $\mathbf{Q}$ & M72 \\
\hline B & 1.4632 & 1.4436 & 1.4372 & 1.4203 & 1.3891 & 1.3765 & 1.3762 & 1.3351 & 1.3344 & 1.3150 & 1.2958 & 1.1499 \\
\hline
\end{tabular}

5. Comparison and analysis of the impact of P85 value added increase on the total output required for equilibrium in the national economy.

Table 20 contains two arranged (from largest to smallest) excerpts from the Ghosh inverse $\Gamma$ : arrangement by LVA indicators and arrangement by FIN indicators.

The contents of Table 20 confirm, from another point of view, the conclusion made before on the basis of Tables 18 and 19. All considered countries - EST, FIN, LVA, LTU have to be qualified as industry with low total forward linkage: TFL(EST_P85) $=1.08 ; \quad$ TFL(FIN_P85) $=1.11$; TFL $\left(L V A \_P 85\right)=1.08$; TFL $\left(L T U \_P 85\right)=1.05$. That conclusion indicates a relatively small impact on the rest national industries caused by the value added increase in P85 causes. Namely, if the industry P85 would be able to increase its value added when value added of all the other industries remains 
unchanged, the required balanced growth of all the rest national industries gross outputs to ensure economic equilibrium is not unrealistic and can be attained.

Table 20

Industry's P85 ten biggest Gosh coefficients for LVA and FIN

(components of the vectors $\boldsymbol{\Gamma}_{j}$.)

\begin{tabular}{|c|c|c|c|c|c|c|c|c|c|c|c|}
\hline & P85 & 3 & $\mathrm{~F}$ & G46 & H52 & G47 & M6s & $\mathrm{N}$ & D35 & $\mathrm{H} 49$ & TFL \\
\hline EST & 1011 & 023 & 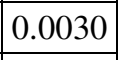 & 0 & 0 & 0.0027 & & & & & 774 \\
\hline FIN & 0176 & & 1 & 7 & 0. & 0. & & & & & 1128 \\
\hline A & 10 & 101 & 4 & 1 & 0 & 0 & & & & & 46 \\
\hline LTU & 0063 & \begin{tabular}{|l|l|}
0.0005 \\
\end{tabular} & 0.0015 & 0.0023 & 0.0020 & 0.0057 & 0.0012 & 0.0007 & 0.0003 & 0.0008 & 1.0518 \\
\hline
\end{tabular}

\begin{tabular}{|c|c|c|c|c|c|c|c|c|c|c|}
\hline & P85 & C26 & Q & O84 & R_S & J62_J63 & G47 & G46 & M69_M70 & L68 \\
\hline EST & 1.0117 & 0.0010 & 0.0021 & 0.0111 & 0.0043 & 0.0022 & 0.0027 & 0.0026 & 0.0012 & 0.0014 \\
\hline FIN & $\mathbf{1 . 0 1 7 6}$ & $\mathbf{0 . 0 1 7 1}$ & $\mathbf{0 . 0 1 2 4}$ & $\mathbf{0 . 0 1 2 1}$ & $\mathbf{0 . 0 1 0 8}$ & $\mathbf{0 . 0 0 5 8}$ & $\mathbf{0 . 0 0 3 2}$ & $\mathbf{0 . 0 0 2 7}$ & $\mathbf{0 . 0 0 2 7}$ & $\mathbf{0 . 0 0 2 2}$ \\
\hline LVA & 1.0100 & 0.0001 & 0.0008 & 0.0015 & 0.0014 & 0.0101 & 0.0038 & 0.0071 & 0.0035 & 0.0019 \\
\hline LTU & 1.0063 & 0.0000 & 0.0096 & 0.0022 & 0.0010 & 0.0005 & 0.0057 & 0.0023 & 0.0012 & 0.0008 \\
\hline
\end{tabular}

6. The main opportunity and main obstacle of Latvia's higher education export as a type of business.

As it was concluded above, an increase in value added of the Latvian industry P85 (like in EST, FIN, LTU) can be obtained as a result of education product final demand increase. Naturally, the final demand increase implies direct need for gross output increase, but the important detection of our studies shows that final demand increase does not require (through interindustry links) exorbitant conditions to the rest national economy. The intermediate consumption cost reduction is not a topical problem right now, because the total intermediate consumption with respect to monetary unit of output in LVA is 0.2277, while in EST this indicator equals 0.2579, in FIN - 0.2454, in LTU - 0.1810.

The final demand increase in P85 leads directly to the value added increase. Due to demographic shortage in Latvia it is most realistically to conclude that the final demand growth (at least in some professions) can be attained through the higher education exports.

The idea about the necessity to export higher education has often been expressed in Latvian mass media, but, unfortunately, has not been transformed in actions. The disagreeable reason of that is the misunderstanding of the Latvian higher education exports market. The heart of the matter is: (a) offered higher education in English as a business product is not compatible in the world's higher education market; (b) due to the adverse status of the Russian language the export of higher education in Russian is not allowed.

The prohibition to export higher education in Russian is a rude mistake that weakens the education export as a type of business especially appropriate for Latvia. Indeed, it is easy to verify that Latvia is able to offer higher education in subjects focused on fields, such as Applied Social Sciences, Regulation, Cybernetics, Computational Economics or Computational Social Sciences (STEMLE - Science, Technology, Engineering, Mathematics, Law and Economics). The Latvian education institute is able right now to welcome and to teach a big number of foreign students. The staff of universities and high schools often have not full working week, the rooms often are almost empty. The only condition is the real demand for higher education and profitable sales. During the conference about export of education held on 05.12.2018 in Turība University (www.turiba.lv) it was reported that direct average purchases (payments for studies, direct living costs) per each foreign student are approximately 11000 euros. Latvia would be able to earn a lot of money by exporting higher education. For example, the author dares to assert that at the Ventspils University of Applied Sciences, where he has been working for 20 years, the Faculty of Economics and Management is able to welcome about 100 foreign students each year by offering to buy education in subjects of Economics and Business: Business, Finance, Economics, Industrial Relations \& Labour, Management, Operations Research \& Management Science according to the Organisation for Economic Cooperation and Development (OECD) Classification. As a result, about 400 foreign students would enriched the Faculty and left more than 4 million euros in Ventspils city each year. Besides that, the 
private contacts between Latvian students and students from Russia, Uzbekistan, Kazakhstan and other East countries are a sufficient and real precondition for fruitful business contacts in the future, after graduated studies in the Ventspils University of Applied Sciences.

The prohibition to export higher education in Russian mixes up exaggerated political precaution, on the one hand, and vitally important Latvian business and welfare interests, on the other hand. The author would like to appeal to colleagues to support the request for wide gate permission to export higher education in Russian.

\section{Conclusions}

1. The comparative analysis of value added created by the industry P85 (Education) in the Baltic States (EST, LVA, LTU) and Finland (FIN) demonstrates the fundamental analogy, namely, almost all value added is ensured by government purchases (CONS_g), but the role of export is misery.

2. The economic analysis leads to the main conclusion: the most realistic tool to increase value added in the Latvian P85 is well-organized marketing in order to expand the higher education exports, because the final demand increase in P85 does not require exorbitant conditions to the rest national economy but at the same time leads directly to an increase in value added.

3. The main opportunity and main obstacle for exporting Latvia's higher education as a type of business are, on the one hand, the real capacity to export higher education in Russian (for example, the subjects of STEMLE) due to qualified teaching staff and satisfactory infrastructure and, on the other hand, the official prohibition to export higher education in Russian due to exaggerated political precaution.

\section{References}

[1] Leontief W. Input-Output Economics. Second Edition. - Oxford University Press. 1986, $436 \mathrm{pp}$.

[2] Ghosh A. Input-Output Approach to an Allocation System. - Economica, Vol. 25, No. 1, 1958, pp. 58-64.

[3] Ronald E. Miller, Peter D. Blair. Input-Output analysis. Foundations and extensions. Second Edition. - Cambridge University Press, 2013, 750 pp.

[4] Timmer M. P., Dietzenbacher E., Los B., Stehrer R., de Vries G. J. An Illustrated User Guide to the World Input-Output Database: the Case of Global Automotive Production. - Review of International Economics, vol. 23, 2015, 575 pp.

[5] Blomqvist Ä., Wonnacott P., Wonnacott R. Economics. Third Canadian Edition. - McGraw-Hill Ryerson Limited, 1990, 795 pp.

[6] Jaunzems A. Comparative dynamic analysis of value added created by industry "forestry and logging" in the Baltic states and Finland. 17th International Scientific Conference on Engineering for Rural Development. Proceedings, Latvia, Jelgava, 2018, pp. 1019-1028.

[7] European Central Bank. All glossary entries - V. [online][16.02.2019] Available at: http://www.ecb.europa.eu/home/glossary/html/glossv.en.html.

[8] Eurostat. Intermediate consumption. [online][16.02.2019] Available at: http://epp.eurostat.ec.europa.eu/statistics_explained/index.php/Glossary:Intermediate_consumptio n.

[9] Eurostat. Gross value added. [online][16.02.2019] Available at: http://epp.eurostat.ec.europa.eu/statistics_explained/index.php/Glossary:Gross_value_added. 